\title{
Gritos en la piel, sonidos del dolor. A propósito de Zona de Dolor 1 de Diamela Eltit
}

\section{Screams in the Skin, Sounds of Pain. About Zona de Dolor 1 by Diamela Eltit}

\begin{abstract}
Resumen
Abordando una perspectiva teórica proveniente de la disciplina teatrológica, el escrito tiene por objetivo realizar un análisis de la performance Zona de dolor 1 o "Maipú" de Diamela Eltit de 1980. Para ello me detengo en la piel, el cuerpo, la voz y el dolor como superficies de una experiencia sensible generadora de conocimiento que se perciben del visionado del video disponible de la performance. El análisis de la performance requiere de un rescate historiográfico en el que se discuta la parcialidad con que el concepto de "escena de avanzada" (Richard) interpretó Zonas de dolor (1980 y 1982), situando una lectura de las filiaciones y entrecruzamientos de Eltit con Ronald Kay y el seminario que le dedicó a la sabiduría de Antonin Artaud el año 1974. El pensamiento en torno al cuerpo, la carne y el dolor del teatrista francés acompaña las siguientes reflexiones y permiten presentar el poder de lo performativo en la voz de Diamela Eltit en algunas escenas del video de Zonas de dolor 1.
\end{abstract}

Palabras claves

carne, lo performativo, cuerpo, cualidades de la voz, teatrología, Zona de dolor

\begin{abstract}
Addressing a theoretical perspective from the Theatre Studies, the writing aims to perform an analysis of the performance Zona de dolor 1 or "Maipú" by Diamela Eltit from 1980. To do this, I stop at the skin, the body, the voice and the pain as surfaces of a sensitive experience generating knowledge that are perceived from the viewing of the available video of the performance. This performance analysis requires a historiographic rescue in which the partiality with which the concept of "escena de anvanza" (Richard) interpreted the performances Zonas de dolor (1980 and 1982) is discussed, situating a reading of the filiations and crossings of Eltit with Ronald Kay and the seminar that he dedicated to the wisdom of Antonin Artaud in 1974. The thought about the body, the flesh and the pain of the French
\end{abstract}


teatrist accompanies the following reflections and allows to present the power of the performative in the voice of Diamela Eltit in some in some scenes from the video of Zona de dolor 1.

Keywords

flesh, the performative, body, quality of the voice, Theatre Studies, Zona de dolor

\begin{abstract}
"No comparto mucho el concepto de alma, pongamos el cuerpo, más que poner cuerpo y alma, pongamos el alma adentro del cuerpo, como un órgano más... El cuerpo va a hacer siempre un botín, entonces en la medida que lo pienses más y no tengas ninguna ingenuidad sobre la construcción corporal puedes entrar de una manera más política". Diamela Eltit
\end{abstract}

En una reciente conversación en la Universidad Diego Portales, Diamela Eltit recibió la siguiente pregunta de su entrevistador, ¿por qué ir a leer a un prostíbulo? Su respuesta fue: "en ese momento pensaba que el libro era insuficiente, que era un objeto insuficiente, que era agobiante, una especie de celda. Mis preocupaciones giraban en torno a una expansión del libro... Yo pensé qué pasa si desplazas lo literario a otro espacio y a este lugar que tiene muchas marcas"1. En objetivo del presente ensayo es instalar esta reflexión general en aquella expansión a la que aludía Diamela Eltit. Para ello me dispongo a presentar algunas de las herramientas de análisis que proponen las investigaciones teatrológicas contemporáneas, particularmente de lo que Erika Fischer-Lichte ha denominado como una Estética de lo performativo (2011), en torno a un visionado de un video de la "performance" / acción de arte Zona de dolor 1 performada por Diamela Eltit en un prostíbulo el año 1980. El ensayo está divido en tres (3) partes. La primera quiere instalar los modos en que el teatrólogo se hace cargo del material, las fuentes para el posterior análisis de su “objeto" de estudio. De interés, en esta primera parte, resulta la detención en las cualidades del cuerpo, la piel, el dolor que se desprende

\footnotetext{
${ }^{1}$ La entrevista se puede revisar en: $\underline{\text { https: } / / w w w . y o u t u b e . c o m / w a t c h ? v=J e l E h i H A H B I \& t=1215 \mathrm{~s}}$
} 
del video antes citado. Además de dar cuenta del valor que tiene el formato audiovisual para la investigación teatrológica. En la segunda parte, resulta necesario re-orientar una lectura historiográfica de las Zonas de dolor, respecto a algunas de las filiaciones artísticas y teóricas que generó Eltit tanto con Roland Kay como, en particular, con la lectura de algunas de los obras de Antonin Artaud. En ello es necesario situar y debatir con la lectura presentada por Nelly Richard y su, ampliamente difundido, concepto de "escena de avanzada". Finalmente se retoma la especificidad de Zona de dolor 1 o "Maipú" en clave artaudiana con el objetivo de analizar las intensidades sónicas de la voz de Eltit como gritos de la piel y/o sonidos del dolor desde la perspectiva de lo performativo.

\section{Tentativa teatrológica del cuerpo en la piel/en el dolor}

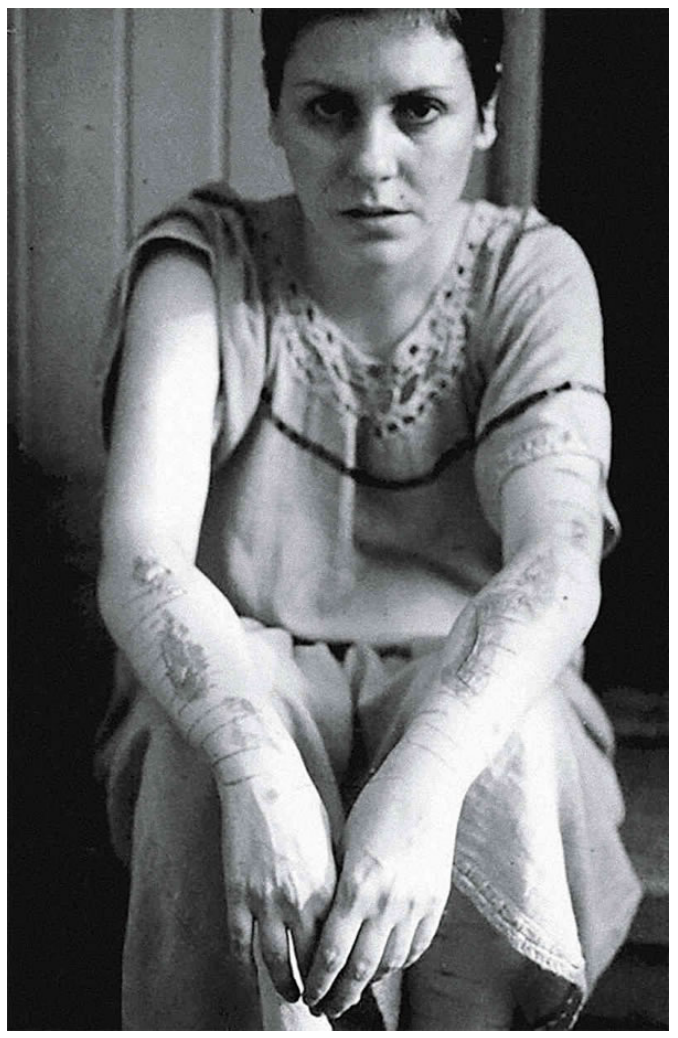

Ilustración 1. Zonas de Dolor 1 
CATEdRal Tomada: Revista de crítica literaria latinoamericana / Journal of Latin American Literary Criticism Gritos en la piel, sonidos del dolor. A propósito de Zona de Dolor 1 de Diamela Eltit

\section{Trazos y cortes del video Diamela Eltit -Zona de Dolor ${ }^{2}$ :}

"Fotografías editadas en video editado. La cámara registra la imagen, la escanea de cabeza a pies. Un cuerpo femenino magullado, cortado, ensangrentado y moreteado aparece en el soporte audiovisual. Son sus brazos y pies los que contienen la impronta del corte. En el minuto 1:27 la imagen en movimiento inserta un cambio. Al cúmulo de fotografías que presenta en su inicio el video se anexa la emergencia constante, intensa, rápida de una voz aguda, oscilante, a un ritmo persistente, intenso con la que lee un manuscrito. De pronto se aparecen imágenes en movimiento de una cámara que graba dentro de un espacio oscuro desde el cual se perciben tres contornos femeninos situados en el umbral que divide al espacio desde el que se filma de un espacio desde el que performa un cuerpo femenino. Éste último proyecta luz hacia la cámara, más, en un inicio, un grupo de 3 cuerpos femeninos situados en el umbral no permiten determinar qué hay en ese otro espacio. La cámara comienza a moverse, a buscar un ángulo en elevación para poder determinar un cuerpo que, sentado, genera movimientos con uno de sus brazos, tocándose la frente, el cabello y que se agita levemente mientras se logra percibir el movimiento de sus labios y la lectura. En el minuto 2:06, el plano varía, de pronto el espacio de acá se transforma en el espacio de allá y nos encontramos de frente a la mujer que lee, siempre en voz alta, con un tono persistentemente agudo, continuo, rápido, incesante e inquietante, in-soportable unos papeles que sostiene con su mano derecha, mientras continúa restregando su brazo izquierdo contra su frente y cabello. Ahora logramos determinar que la mujer está sentada sobre una silla roja y que una de sus piernas se sitúa sobre otra silla similar a la primera. $\mathrm{Su}$ voz persiste, leyendo en una frecuencia aguda y oscilante, de unos papeles. Vemos como el haz lumínico de un foco quema su rostro y proyecta la sombra de su cuerpo en una pared. De pronto, el cuadro de la cámara se acerca al cuerpo que no para de leer estridentemente las líneas de un cuerpo mutilado. La

\footnotetext{
${ }^{2}$ El video en cuestión se puede revisar en: https:/www.youtube.com/watch?v=esxS9dg1S3c\&t=8s
} 
cámara la filma de cerca, desde un costado, lo que permite apreciar como la sombra de la cámara y el/la camarógrafa se mezcla con la sombra de la mujer. Este gesto tecnológico, mediado por el video, proyecta una segunda sobra en la pared, producto, seguramente, de un segundo foco de luz proveniente del costado contrario a la acción de arte"3.

Una "zona" es definida como una superficie acotada, que se distingue de lo

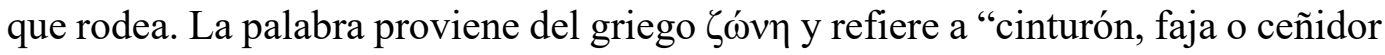
de un cuerpo" (RAE). Además es en la disciplina de la geografía, donde se utiliza con mayor interés, refiere a la segmentación de los cinco puntos de la superficie terrestre a raíz de los trópicos y los círculos polares. El "dolor", por otra parte, apunta a una sensación localizada y subjetiva que percibe el cuerpo humano. Por lo general, esta percepción sensible genera un desagrado, un malestar en el cuerpo del que la percibe, dejando emerger un sentimiento intenso (de pena, rabia, tristeza, y/o de lástima) tanto a quien experimenta la emoción como a quién se transforma en espectador del dolor ajeno. El dolor, en esto términos, genera altos grados de empatía que afecta a las señales del sistema nervioso, transformando el cuerpo de quien lo padece.

Estoy interesado en el modo en que se define una "zona" toda vez que se delimita y distingue al mismo tiempo un espacio-tiempo (una superficie de experiencia), generalmente en términos geográficos. Se trata de una demarcación, de un punto de referencia, de un límite que ciñe, protege y proyecta. Ahora, esa zona de dolor, entonces, buscaría delimitar y proteger una superficie de experiencia en términos que la experimentación de una emoción subjetiva e intensamente vivenciada en el cuerpo tenga un grado de proyección empática en otros cuerpos. Así este padecer empáticamente compartido, pero distinto, se transforma en la performance Zona de dolor 1, en "una zona de riesgo"... que posiciona la

${ }^{3}$ Este texto corresponde a un ejercicio escritural de descripción (de un cuadro) en el que voy desprendiendo cualidades que llaman mi atención mientras apreciaba el video Zonas de dolor 1 . Se trata de una práctica habitual en disciplinas como la teatrología o la etnografía y tiene por finalidad desprenderse de la construcción de significados y símbolos remarcando y poniendo atención en la emergencia y los efectos que emergen de mi experiencia de visionado (generalmente en formato de video, DVD). 
emergencia subjetiva de quien percibe el cuerpo humano basado en la intensidad sensible.

Siguiendo lo planteado por Mónica Barrientos en su ensayo "La construcción estética de la imagen en Zonas de dolor de Diamelta Eltit”, el video, que estamos revisando para el presente ensayo, está compuesto de tres momentos que solo presentan dos momentos de la lectura de Lumpérica que realizó Eltit en el marco de su Zona de dolor $I^{4}$.

Concuerdo parcialmente con lo que, respecto al uso del video, plantea Mónica Barrientos en su análisis de Zonas de Dolor:

el uso del video en relación a la acción de arte demuestra una estética que precariza el documento histórico al exponer de manera reflexiva -por medio del uso del montaje, la yuxtaposición de imágenes y el collage de sonidos- la naturaleza construida de la narrativa y la verdad histórica. El video combina la performance original con las fotografías tomadas de diferentes sitios y momentos, alterando el tiempo real de la acción de arte a través del proceso de edición. De ese modo, deja fuera muchos fragmentos de la acción de arte original, como fue la interacción del personaje (Eltit) con la audiencia y el sonido de fondo no sincronizado con la imagen. (La construcción estética 149)

Si bien es cierto que el uso del video precariza el modo en que nos vinculamos con los hechos pasados, es igualmente cierto que las lecturas que hagamos de los documentos históricos (dentro de los cuales se debe contar el

\footnotetext{
${ }^{4}$ Zonas de dolor de Diamela Eltit estuvo compuesta de 2 acciones/performances. La primera, y que revisamos en este escrito, se realizó el año 1980 y se materializó en un prostíbulo de la calle Maipú. La segunda, de 1982, involucró la acción de Eltit de besar a mendigo en la vía pública de Santiago y fue nombrada como "Trabajo de amor con un asilado de la Hospedería de Santiago". Las acciones/performances se solían llamar como "Maipú", la primera, y "El beso", la segunda. Para esta descripción, ver Barrientos, Mónica "La construcción estética de la imagen en Zonas de dolor de Diamelta Eltit".
} 
video!), y me imagino que Barrientos se refiere a fuentes escritas ..., también pueden caer en esa misma precarización respecto a lo que efectivamente ocurrió y, por lo tanto, a la búsqueda de una "verdad histórica". Me parece, si bien es bueno tener claro y exponer lo que cualquier fuente genera a la experiencia vivida, la pretensión investigativa de una verdad histórica tiende a nublar o acotar las posibilidades de analizar un hecho del pasado en el presente.

No cabe duda que tener claro esto y partir cualquier investigación desde esta "precariedad" (que, así lo quiero proponer, no es más que una posibilidad, no como una falta de...) resulta necesario, además de tener claro que no hay ningún documento histórico que pueda equipararse a la experiencia resultante de el en $v i v o^{6}$. La disciplina teatrológica tienen esta distinción clara, toda vez que su "objeto" de estudio es el acontecer escénico o performance, además de las estrategias de escenificación que elabora un grupo artísticos tanto antes como después de cada función. Este carácter efímero de las artes escénicas le permite a la teatrología el hacer uso de la dimensión performativa para sus análisis de cada performance bajo el nombre genérico de análisis de la performance ${ }^{7}$.

Mi apuesta por el video en el análisis parte de la idea general que no nos podemos hacer cargo como investigadores de vivencias que no experimentamos, pero que sí podemos articular tanto documentos históricos escritos como fotografías, programas, criticas, cuadernos de proceso y videos como partes constitutivas del quehacer investigativo, toda vez que el acceso y revisión de todas estas fuentes son, en sí y de por sí, una vivencia que va dejando huellas en nosotros a la hora de utilizarlas para analizar un hecho del pasado. Aquí, así mi punto de vista, se proyecta una posibilidad de análisis de fenómenos del pasado con el objetivo de revalidar nuevas formas de trabajo historiográficas para las Artes.

${ }^{6}$ Asunto desde el que la teatrología elabora la mayor parte de sus perspectivas y estrategias de análisis dado que su "objeto" de estudio es el acontecer escénico o performance.

${ }^{7}$ La literatura es amplia, destaco un par de referencias fundamentales: Martin, Jacqueline and Sauter, Willmar. Understanding theatre: performance analysis in theory and practice. Berghaus, Günter. New approaches to theatre studies and performance analysis. Fischer-Lichte, Erika. Estética de lo performativo. 
CATEDRAL TOMADA: Revista de crítica literaria latinoamericana / Journal of Latin American Literary Criticism Gritos en la piel, sonidos del dolor. A propósito de Zona de Dolor 1 de Diamela Eltit

Sin embargo, es altamente sugerente, como lo plantea acertadamente Barrientos, ser conscientes y remarcar que el video que se está analizando es una "realidad alterada" (La construcción 2017), toda vez que el lente de la cámara que lo grabó, seleccionó solo algunos ángulos de la experiencia además de tratarse de un video editado (la acción de Eltit no tardó 15 minutos) en que la selección de imágenes tampoco calza con los particulares sonidos que emite Eltit al leer los fragmentos de su libro, a la fecha aún no editado, Lumpérica, ni, como lo sostiene Barrientos, con los sonidos ambientales y las interacciones de Eltit (para quien investiga el teatro, resulta paradójica la descripción de las acciones, los movimientos y la presencia física de Diamela Eltit como "un personaje") con quienes fueron parte constitutiva de la performance esa noche.

\section{Contexto de filiaciones y entrecruzamientos artísticos: Zonas de dolor en perspectiva historiográfica}

Resulta del todo oportuno y necesario partir por delimitar una lectura y contextualización de Zonas de Dolor en la que se proponga una recuperación historiográfica para poder analizar la acción de arte de Diamela Eltit de 1980 y 1982 tanto desde otra matriz de filiaciones artísticas como desde otras perspectivas metodológicas. Al plantear este trayecto, resulta, no solo poco prudente, sino ineficiente no tratar de hacerse cargo de la lectura que propusiera Nelly Richard respecto a la denominada "escena de avanzada", en particular lo referido en el capítulo "retóricas del cuerpo" de su libro Márgenes e Instituciones y, además, desde el prólogo que Richard escribe para una edición posterior a la primera edición de Lumpérica ${ }^{8}$.

Hacerse cargo del marco referencial y la construcción teórica de un concepto como el de "escena de avanzada" se enmarca en un "claro reconocimiento

\footnotetext{
${ }^{8}$ En particular, me refiero a la edición de editorial Planeta del año 2008 que estoy revisando para este artículo.
} 
de inscripción en los relatos sobre artes visuales en Chile"9. Esta inscripción despliega no solo una lectura de diversas prácticas artísticas que utilizan el cuerpo como soporte para la creación de múltiples y variadas acciones de arte durante la dictadura cívico-militar chilena, sino que propone marcos teóricos de inscripción disciplinar respecto a la reflexión sobre las Artes en Chile. El tema que se inscribe con mayor fuerza, y con razón, en este contexto es el cuerpo. Así:

El cuerpo como soporte de intervención artística en la escena de "avanzada" sirvió para que afloraran vastos estratos de significación que permanecían bloqueados por la censura ejercida sobre el lenguaje...” el cuerpo abre un registro de polivalencias expresivas que escapa a las restricciones impuestas por el monopolio lingüístico, abarcando partículas asignificantes y flujos trans-semióticos. (Márgenes 86-7)

Por otro lado, en la ponencia sobre "Lo político en el Arte: arte, política e instituciones" leída en el Instituto Hemisférico de Performance y Política en New York, Richard circunscribe el "corte neovanguardista" de la escena de avanzada ${ }^{10}$ en su capacidad de:

reformular, desde fines delos años 70, mecánicas de producción creativa que cruzaron las fronteras entre los géneros (las artes visuales, la literatura, la poesía, el video y el cine, el texto crítico) y que ampliaron los soportes técnicos del arte al cuerpo vivo y a la ciudad: el cuerpo, en el arte de la performance, actuó como un eje transemiótico de energías pulsionales que

\footnotetext{
${ }^{9}$ Peters remarcó lo que un concepto como el de "escena de avanzada" "significó, para el sistema artístico nacional, la marca/inscripción de un conjunto de artistas, aparentemente desconexos, en el aparato escritural e histórico (memoria) de las artes visuales nacionales" (4). Ver la tesis de magíster de Tomás Peters bajo el título "Cartografía de una puesta en escena. De la enunciación de un concepto a su inscripción en los relatos: sobre cómo el concepto de Escena de Avanzada se describe/inscribe en la historia del arte chileno".

${ }^{10}$ Eugenio Dittborn, en entrevista con Federico Galende, divide a la escena de avanzada en tres núcleos: "Estábamos Catalina (Parra), Kay y yo por un lado; Altamirano, Leppe y Nelly por otro y después el CADA" (Filtraciones 1 140).
} 
liberaron - en tiempos de censura - márgenes de subjetivación rebelde, mientras que las intervenciones urbanas buscaban alterar fugazmente las rutinas callejeras con su vibrante gesto de desacato al encuadre militarista que uniformaba el cotidiano. (Richard) $)^{11}$

La lectura que presenta Nelly Richard del cuerpo para lo que ella denominó como escena de avanzada, adquiere valor para la reflexión teórica de las artes toda vez que de las prácticas artísticas seleccionadas por ella se desprenden "estratos de significación" del cuerpo que, como arte de la performance, permite liberar "energías pulsionales" que habían sido anuladas o hechas desaparecer por la violencia dictatorial. Así planteada la lectura, resulta necesario remarcar, al menos en esta primera aproximación al problema, preguntas respecto al tratamiento que hace Richard de esas "polivalencias expresivas" que "cruzaron las fronteras entre los géneros". La perspectiva disidente que planteo respecto a la lectura del cuerpo apunta a dos grandes áreas: en primer lugar, al modo en que Richard busca instalar "el olfato semiológico" (Filtraciones 1 186) de las prácticas artísticas, en particular de la "fascinante inteligencia de los signos" que proponía Carlos Leppe, que configuran su modo de instalación de la escena de avanzada como categorización que engloba un cúmulo disímil de prácticas artísticas; y, en segundo lugar, en su validación de los usos que, diversos artistas, hacen del cuerpo, basados en un legítimo entrecruzamiento de disciplinas que, sin embargo, excluyen a las artes escénicas del teatro y la danza (siendo estas formas de arte las que no sólo trabajan preponderantemente con o en el cuerpo, sino que, como veremos a continuación, la referencia a Antonin Artaud es fundamental para entrar en diálogo con Zonas de dolor de Diamela Eltit. Mi punto, aquí, es: hubo un gran número de artistas que instalaron de modo multi-disciplinar y ampliado el tema y los usos del cuerpo como soporte y práctica de "obra" (el ser el cuerpo el centro desde el que se emerge la propuesta artística, la "obra” recae en ArteAcción o Performance). Además que,

\footnotetext{
${ }^{11}$ Ver: https://hemisphericinstitute.org/es/e-misferica-62/richard.html.
} 
todas estas prácticas artísticas contienen grados de filiaciones y entrelazamientos artísticos con grupos y tradiciones y disciplinas artísticas muy diversas. Y, finalmente, parte de estos grupos, tradiciones y disciplinas artísticas, en el caso de los modos en que Diamela Eltit presenta el cuerpo como ArteAcción, está directamente vinculado con los nombres de Ronald Kay y Antonin Artaud.

Es la propia Diamela Eltit la que describe las diferencias de lectura con Richard a partir del modo de pensar y practicar dos elementos fundamentales en torno a esta "verdadera ruptura artística y teórica" (Filtraciones 1 188) que levanta el arte chileno en tiempos de dictadura: 1 . El cuerpo/la carne y 2. la función que debía cobrar el arte en la sociedad. Respecto al primero, Eltit, muy en sintonía con lo planteado por Antonin Artaud, sitúa su interés por el cuerpo en la carne. En su novela Lumpérica, Eltit se sumerge en los recovecos, densidades y sensaciones de la vivencia con/en la carne. Un ejemplo de ello lo encontramos en la parte 3 del libro, cuando se describe larga y detalladamente el vínculo orgánico entre el cuerpo animal y el cuerpo humano: "Sudor contra sudor penetraría, salobre gusto el roce de la carne hasta la herida sin sus ancas los soportara sin montura" (Lumpérica 73). O más adelante: "Se tiende entera sobre el suelo helado, deja que sus pelos se separen rompiendo la mezcla que el sudor ha construido sobre su superficie." (75). Y, quizás, el momento de más cercanía a la escritura orgánicamente comprometida con la carne de Artaud, sea en "Ensayo General", donde Eltit, después de situar la fotografía en la que se presenta sus brazos y pies cortados y ensangrentados, describe una minuciosa observación, cargada de sensibilidad de cada uno de las líneas o cortes que se infirió en su propia piel/carne para la performance en el prostíbulo. Las líneas, concepto que parece persistentemente en el relato, son descritas por Eltit en Lumpérica invocando la experiencia vivida durante la acción:

el segundo corte del brazo izquierdo es manifiestamente más débil. La hoja se ha hundido en la piel de manera superficial - Este segundo corte está regido por el primero del brazo izquierdo. La distancia que separa los dos cortes es la superficie de la piel que aparece y emerge siguiendo 
rigurosamente la forma propia de la muñeca" $[\ldots]$ ¿Es realmente un corte? Sí, porque rompe con una superficie dada. Sobre esa misma superficie el corte parcela un fragmento que marca un límite distinto. El corte debería verse como límite. El corte es el límite. (175-177)

Respecto al segundo elemento fundamental, la función que debe cumplir el arte en la sociedad, Eltit rescata "el tema de Nelly es la necesidad de mediación, la elipsis, porque considera que la confrontación directa empobrece la obra"... "Además, yo creo que ellos tenían pánico a la política...en términos de que la política contingente podía entorpecer y limitar estéticamente sus trabajos" (Filtraciones 1 223). Por otro lado, el sociólogo Fernando Bacells inscribe su lectura de la función escritural de Richard a propósito de la dicotomía función que debía tener el arte en la sociedad. Para Bacells, Richard estuvo:

adscrita inicialmente a la tesis de la autorreferencialidad de la historia del arte, en el estilo de la teoría progresista de que la ciencia avanza de error a verdad y un clavo saca a otro clavo, tuvo en ese tiempo dificultades para entender procesos sociales particulares, sin patrón aritmético y sujetos a interdependencias culturales y sociales contradictorias. (Neustadt 71)

Tanto Eltit como Bacells presentan puntos de vista disidentes al modo en que Richard instalo su lectura del arte "de avanzada", en particular de las acciones de arte del C.A.D.A. La mediación que propone Richard para la obra de arte entra en conflicto con aquella "confrontación directa" que proponían los integrantes de C.A.D.A. Ellos aludían a aquel "tema de la ciudad" (Piña 213) en el que la obra se transformada en una experiencia directa que perseguía re-articular a una sociedad asfixiada por la violencia cívico-militar.

Manteniendo presente estos énfasis de lectura e interpretación disímil al trazado por Richard, me parece fundamental relevar un conjunto de filiaciones y entrelazamientos artísticos que tienen su semilla en el seminario Signometraje que 
Ronald Kay le dedicara al teatrsita francés Antonin Artaud en el Departamento de Estudios Humanísticos el año $1974^{12}$. Considero que esta línea de pensamiento puede entregar diversas luces y una contextualización focalizada a la lectura historiográfica para la historia del arteacción que deseo proponer tomando como ejemplo a Zona de Dolor 1 de Diamela Eltit. Para ello retomo lo que ha planteado Robert Neustadt en su libro dedicado al Colectivo Acciones de Arte de la siguiente forma: "es probable que las ideas teóricas de R. Kay hayan contribuido a desarrollar las estrategias semióticas del C.A.D.A de explorar nuevas formas de expresión" (28). Esa probabilidad adquiere un particular peso si se piensa que Eltit participó como estudiante de los seminarios dictados por Kay en el Departamento de Estudios Humanísticos. Cursos, como los recuerda Eltit, "que traían una propuesta nueva, para nosotros al menos, esencialmente interdisciplinaria: happenings, cine y visualidad" (Piña 212).

En esta línea de filiaciones, la influencia de Kay y las lecturas que hicieran del Teatro y su Doble y otros escritos de Antonin Artaud es, así mi presunción, clave si se quiere determinar el modo de producción y la performance de Eltit. Al respecto, una en una entrevista concedida a Andrés Piña, Eltit se refiere a sus experiencias como estudiante con Kay, particularmente al trabajo que realizaron con algunos textos de Antonin Artaud del siguiente modo:

primero una lectura bastante acotada de El teatro y su doble de Artaud y de otros escritos de él que se relacionan con el trabajo del cuerpo. Finalmente terminamos escenificando Los Cenci...Estábamos en un momento bastante ultra, porque representábamos esta obra en francés. El objetivo no era hacer un montaje en un idioma determinado, sino actuar

${ }^{12}$ Cabe remarcar que la conclusión de este seminario de lectura de la obra de Antonin Artuad concluyó con la puesta en escena de la obra, en lengua francesa, Los Cenci del director francés, además de la acción de arte presentaba en el altillo del Instituto de Estudios Humanísticos en octubre del año 1974 bajo en nombre Tentativa Artaud. Ver Vega, Francisco, "Despojos de psique. Trauma, inscripción y archivo en Tentativa Artaud de Ronald Kay". 
en un lenguaje que yo, al menos, no entendía, y ver el funcionamiento del cuerpo no de manera paralela con la acción, sino desfasado. (212)

La cita es reveladora de un modo de trabajo artístico que Kay pretendía entregar a quienes participaron de la escenificación del texto de Artaud, pero, además, la referencia de Eltit a su no entendimiento del francés, lengua en la que escenificaron Los Cenci, con el que su atención interpretativa se concentraba en "el funcionamiento del cuerpo" que se posiciona de un modo desfasado a la acción. Por acción, aquí, se hace referencia a la acción dramática que narra el texto escrito por Artaud, a su lenguaje escrito en un idioma que Eltit no entendía, no podía decodificar y aplicar a la performatividad del cuerpo. Por eso, a la insistencia de Piña para que ejemplifique, Eltit dice: "si yo decía, "me voy a morir", y no tenía conciencia del texto, simplemente lo pronunciaba. Se trata de una nueva experiencia con el lenguaje, porque si tú no conoces un idioma, no puedes inflexionar nada" (212). Aquí la clave de la lectura y puesta en acción de Artaud, la funcionalidad del cuerpo transformada en acción de arte, basada en la simple pronunciación de un lenguaje que no se conoce, que no permite "inflexionar nada", se presenta como agente de producción performativa. Para Artaud, "existen gritos intelectuales, gritos que provienen de la sutileza de las médulas. Eso es lo que yo lamo la Carne. Yo no separo mi pensamiento de mi vida. En cada una de las vibraciones de mi lengua vuelvo a hacer todos los caminos del pensamiento en $\mathrm{mi}$ carne" (El arte 77). Ronald Kay, en su profundo estudio de la obra de Artaud ${ }^{13}$, buscaba potenciar estas sutilezas, basadas en lo que hoy denominamos las cualidades performativas del cuerpo, allí donde emerge la vivencia de su carne. Aquí se potencia la creación artística e instala, junto a Diamela Eltit, un giro de gran relevancia respecto a los usos del cuerpo en el ArteAcción chileno.

Para Richard, en cambio, el cuerpo es entendido como "territorio de cruce" de los "microcircuitos" en el que se tejen las "relaciones intersubjetivas $[\ldots]$ entre

\footnotetext{
${ }^{13}$ De la que, entre otras varias cosas, surge la Tentativa Artaud a fines del año 1974.
} 
lo público [...] y lo privado" (Márgenes 77). Asunto que, para ella, adquiere sentido "en sociedades como la chilena donde el autoritarismo penetra el cotidiano" (77). Así, el cuerpo se transforma en:

un agente material de estructuración de la experiencia que habla distintas lenguas a la vez: es productor de sueños, transmisor de los mensajes que emite la cultura, animal de rutinas, máquina deseante, depositario de memorias, actor en representación-de-poder, trama de afectos y sentimientos, etc... Por ser una zona limítrofe - dividida entre biología y la sociedad, la pulsión y el discurso, lo sexual y sus categorizaciones de género, la biografía y la historia, etc.-, el cuerpo humano obedece las fronteras de sentido que la diversidad social prescribe como normalidad o bien se estrella contra ellas. (78)

En la definición de cuerpo que propone Richard en su "Las retóricas del cuerpo", persiste la necesidad de situar diversas inflexiones en torno al cuerpo, el es que se repite reiterativamente en la cita. Esto da cuenta de un rápido salto al nombramiento y, hasta cierto punto, a la normalización de este nombramiento que estructura la experiencia basada en la inferencia de significados como constructores, no solo de lenguaje, sino de sentido o normalidad y sentido cultural. El "es" que nombra distintos atributos y relaciones con las que el cuerpo construye sentido, delimita sus posibilidades en clave semiótica ("sígnico") y psicoanalítica ("energías pulsionales de liberación") en la que los signos y sus referencia remarcan hitos e instalan aquel "valor crítico de la referencia al cuerpo como soporte artístico"(Márgenes 78). La "avanzada", particularmente en Zurita-Eltit propone "el cuerpo como zona sacrificial de práctica del dolor", mientras el uso del cuerpo por parte de Carlos Leppe es definido por Richard como "zona mimética de camuflaje y simulacro" (78). Ha sido la propia Nelly Richard la que ha indicado su interés por el uso del cuerpo de Eltit, más su lectura contiene "reparos respecto de la retórica sacrificial en la que la envolvía la proyección de Zurita" (Filtraciones 1 
CATEDRAL TOMADA: Revista de crítica literaria latinoamericana / Journal of Latin American Literary Criticism Gritos en la piel, sonidos del dolor. A propósito de Zona de Dolor 1 de Diamela Eltit

190). En el prólogo a Lumpérica, Richard es clara respecto a su lectura del uso del cuerpo por parte de Eltit:

la intercalación de registros entre la pasión del arte y una zona nocturna de comercio sexual intervenida por la palabra sobregirada de literatura daba cuenta del afiebrado proceso de desensamblaje de los géneros artísticos y literarios, a través del cual Eltit fue modelando un trayecto de escrituras móviles que cambian de soportes (la página, el cuerpo, la ciudad, la pantalla, la biografía, la tradición, el margen, etc.) para experimentar roces desconocidos entre diversas y dispersas trazas de inscripción, materialidades significantes, voluntades de forma, aconteceres privados, modelajes estéticos y rupturas político-culturales. (7-8)

De este modo, Richard sitúa su lectura del uso del cuerpo por parte de Eltit un una clave que, a diferencia de lo presentado por Nelly Richard, considero que un rescate de las filiaciones Artaud/Kay para la lectura de los modos en que Diamela Eltit hace uso y presenta su cuerpo en Zona de dolor 1, implica el gesto de detenernos en aquella "sutileza de la médula" en donde "la simple pronunciación" abre canales de conciencia corporal y posible nueva generación de conocimiento, basado en una atlética de la pausa que ponga freno a la aceleración con la que la Modernidad instaló las ideas del mercado y el crecimiento económico. Artaud fue enfático en esto: “...es preciso ir a pasos lentos por la ruta de las piedras muertas, sobre todo para quien perdió el conocimiento de las palabras" (El arte 78). Eltit remarcada su desconocimiento, su no entendimiento del idioma francés para escenificar Los Cenci de Artaud en el marco del seminario dictado por Kay el año 1974. Pienso que Eltit se transformó, así, en quien "perdió el conocimiento de las palabras" y se sumergió en las inflexiones de la carne, su musculatura, gestos y formas de pronunciación como agente de conocimiento. Es el propio Artaud quien en su breve, pero decisivo escrito Posición de la carne publicado en diciembre de 1925 en el número 147 de La Novelle revue francaise, demarca este ir a pasos lentos 
cuando indica que "(p)ara mi, quien dice Carne dice ante todo aprensión, pelo erizado, carne al desnudo con toda la profundización intelectual de ese espectáculo de la carne pura y todas sus consecuencias en los sentidos, vale decir, en el sentimiento" (El arte 79). Estas cualidades que emergen de una actitud fenomenológica con el cuerpo es parte del desorden al que apuntaba Eltit: "Bueno, hacer Artaud en ese contexto era político. La obra de Artaud es una obra que interroga los signos, que desordena. Leer esos textos es político. Es como cuando el mar se va para adentro" (Neustadt 92).

\section{Intensidades de la voz o las resonancias de la voz en Zona de Dolor 1}

En sus "Cartas sobre el lenguaje" de 1931, Antonin Artaud atestiguaba la necesidad de promover y devolver "al lenguaje de la palabra su antigua eficiencia mágica, su esencial poder de encantamiento" (El teatro 147) en la que se le devolviera su lugar a las cualidades de la voz. Quizás la fuente más potente en éste ámbito sea la obra radiofónica Pour en finir avec le jugement de Dieu (1947) con la que Artaud terminó de presentar su estética de la voz y en el que, como lo plantea Allen S. Weiss, son "los gritos, los chillidos, los gemidos y todos los sonidos disonantes del cuerpo humano que estarían equiparados con la palabra hablada" (Phantasmic 16). Lo que me interesa destacar de esta estética de la voz radiofónica en el teatrista francés se deja delimitar, como lo plantea la teatróloga Doris Kolesch, en tres dimensiones: por un lado el trastorno del habla a través del uso vocal, por el otro la posible disolución del sujeto en una polifonía vocal y finalmente, la variedad de formas de posicionamiento vocal, desde el lenguaje corporal hasta gritos, chillidos, gruñidos, maullidos, etc., hasta declaraciones ruidosas y de entonación compleja que llevan a el límite de lo que generalmente se considera un sonido humano ${ }^{14}$. Es en estas tres dimensiones de la colocación de la voz y la resonancia acústica que deseo proponer para analizar Zona de Dolor de Diamela Eltit.

\footnotetext{
${ }^{14}$ Ver Kolesch, Doris, “Listen to the radio. Artaud's Radio-Stimmen(n)”, página 128.
} 
En una entrevista a Mónica Barrientos, Eltit define las Zonas de Dolor de Eltit como "una performance" (No hay armazón 28). El énfasis radica en el "hecho" que no se trata de un libro, sino de "una producción cultural otra" (28). Ya revisamos anteriormente la búsqueda de un formato que involucrara el cuerpo de Eltit como complemente de la obra escrita y lo justificamos históricamente con lo importante que fue el seminario que Ronald Kay le dedicó a Antonin Artaud para el giro y necesidad que tuvo Eltit en transitar del libro al arte acción. Ahora resulta interesante indagar en los aspectos propios del formato "performance", toda vez que el gesto, tanto de Kay, como del CADA y, en particular de Diamela Eltit con su Zona de Dolor, desplazan el soporte y estructuras literarias, poéticas por el ArteAcción como un modo de radicalizar las conexiones efectivas entre Arte y Vida.

No pretendo asumir aquí la discusión en torno al concepto de "performance" 15 , más si considero necesario vincular mis reflexiones en torno al visionado de Zona de Dolor 1 o "Maipú" en el marco del tratamiento que la ha dado la teatrología al concepto de "lo performativo". Desde esta perspectiva resulta necesario dar cuenta, brevemente, del "giro performativo de las artes" que instaló la teatróloga alemana Erika Fischer-Lichte. Este giro ${ }^{16}$ apuntaba, en primer lugar, al modo en que las Artes fueron incorporando un redescubrimiento del cuerpo como eje articulador, soporte fundante de su creación y producción artística, además de sus modos de relación con la sociedad. Esto tiene, en la lectura de Fischer-Lichte, claras referencias en la época de las vanguardias históricas de principios del siglo $\mathrm{XX}$, así como en el movimiento del neo-vanguardia de las décadas del sesenta y setenta. La concepción del cuerpo, en este caso, asume la perspectiva fenomenología de Merleau-Ponty en la que la distinción cartesiana entre sujeto-objeto es desplazada a favor de asumir reflexivamente la materialidad

\footnotetext{
15 He podido tratar este tema en mi ensayo "Performance: ¿disciplina o concepto umbral?”, en revista Apuntes de Teatro.

${ }^{16}$ Para los distintos giros culturales en las Humanidades y Cs. Sociales, ver: Bachmann-Medick, Doris. Cultural Turns: Neuorientierungen in den Kulturwissenschaften.
} 
de la carne como plataforma de vivencias y transformaciones. Por otro lado, este giro también apuntaba a la necesidad de complementar la lectura semiótica con la que diversas disciplinas, pero también la teatrología, analizaba su objeto de estudio. Si la semiótica priorizaba el sentido y significado que se desprenden tanto de un texto escrito (sea en prosa, poesía y/o dramatúrgico) como de los distintos componentes de una puesta en escena (actuaciones, vestuario, escenografía, objetos, etc. $)^{17}$. La rehabilitación performativa que propone el "giro performativo" persigue analizar los fenómenos artísticos y culturales, ya no como "texto", sino como "performances" en las que se busca poner atención al "cómo" más que solamente en el "qué". Fischer-Lichte propone, entonces, la necesidad de complementar las lecturas de los fenómenos culturales como textos con una lectura de éstos fenómenos cuya aproximación es la performance donde las cualidades que emergen del cuerpo pasan a ser parte del universo de análisis interpretativo.

Dentro de esta visión metodológica que abre el concepto de lo performativo, la voz, como parte del cuerpo humano y animal, es un fenómeno performativo por excelencia. Cuando la voz de alguien resuena en un espacio logra desplegar al menos dos dimensiones en la construcción de conocimiento: en primer lugar, aquella en la que los usos de la voz pueden desplegar, según del tipo de escenificación (teatral) que se trate, un tipo particular de ficción, crear partes constitutivas de personajes, roles, además de articular énfasis en el lenguaje y de lo que proponga un texto dramatúrgico determinado. Pero, en segundo lugar, la voz es capaz de articular la presencia física de alguien en un tiempo-espacio presente (en el aquí y el ahora), intensificando, complementariamente al primer uso de la voz y potenciando la posibilidad de generación de efectos sensitivo-sensuales en la experiencia de quienes co-habitan aquel espacio-tiempo.

Algo similar, pero desde otro lugar, puede ocurrir con quien, como es mi caso, revisan el material audiovisual a disposición de Zona de Dolor. Si ya lo revisamos junto a Artaud en términos de las sutilezas del pronunciamiento, es

\footnotetext{
${ }^{17}$ Para una perspectiva de análisis basada en los signos de la escena ver Pavis, Patrice. El análisis de los espectáculos.
} 
retomado por Erika Fischer-Lichte, quien persigue destacar en este segundo uso de la voz es la materialidad del aparecer sensible-sensual de la voz en el instante de su aparecer en nuestra percepción.

En su lectura de Zona de dolor, Nelly Richard rescata la "resomatización de la palabra" que instala la voz, "exacerbada en el grito" (Márgenes 85), de Diamela Eltit. Con estos conceptos y frases, Richard hace uso de la perspectiva de análisis que estoy instalando en mi lectura a Zona de dolor 1, sobre todo cuando enfatiza el desplazamiento de "la función comunicativa del signo a texturas no lingüísticas, llevando la palabra hasta su disolución fonética y gramatical" (85), y situando "al gesto, como una práctica desviante que rompe la linealidad del discurso" materializando "las inscripciones en la piel (85). Sin embargo, esta decisiva perspectiva no es mayormente tratada por Richard. Más bien, se limita a interpretar éstas "trazas sensibles que preceden o exceden el código de la verbalidad" (85) como una estrategia "que apela al dolor como método de acercamiento a un borde de experiencia donde lo individual se une solidariamente con lo colectivo" (83). Esta lectura tiene su culminación en la interpretación del uso del cuerpo que hacen Zurita-Eltit como "huella cicatricial que responde a una moral del sacrificio" $(84)^{18}$. Richard sitúa su interpretación en una esfera semiótica en la que prima la necesidad por delimitar significados de los códigos que arroja una experiencia determinada por sobre "el peso significante" (Barthes) de la voz. La materialidad de la voz, sus "componentes expresivo-formales" pasa, aquí, a un segundo plano, lo que se rescata en las obras es, más bien, Richard: "la interacción de los diferentes códigos de significación y de producción artística" ${ }^{19}$. La perspectiva teatrológica que

\footnotetext{
${ }^{18}$ Richard incluso llega a inferir que la experiencia del dolor, a través del corte de la carne en brazos y pies por parte de Eltit y en el rostro por parte de Zurita, "es el umbral que autoriza el ingreso del sujeto mutilado a zonas de identificación colectiva donde comparte con los marginados los mismos signos de desmedro social que evidencia en carne propia" (Márgenes 83). Desde esta perspectiva la lectura de Zonas de dolor se ve reducida a la identificación que la/el artista genera al cortarse, dañarse la carne de su propio cuerpo con el objetivo, en la lectura de Richard, de redimir un vinculo con el colectivo marginado y, más allá, con "la cicatriz nacional" (83).

${ }^{19}$ He extraído esta cita de la sugerente tesis doctoral de César Zamorano bajo el título "Revista de Crítica Cultural: pensando (en) la transición”. University of Pittsburgh, 2014. 25 de abril, 2019.
} 
elabora Fischer-Lichte con el concepto de lo performativo busca posicionarse en éstas "trazas sensibles que preceden o exceden el código de la verbalidad" (85), situando el problema de los excedentes la verbalidad en las intensidades (cualidades) de la voz.

Fue justamente Jacques Derrida quien entendió, ciertamente persuadido por Antonin Artaud, el déficit en el que cae el lenguaje gramaticalmente ordenado cuando se percibe el salto al que nos conduce la concentración en la sonoridad vocal por sobre el código de significados que estructuran el lenguaje. En palabras de Derrida:

Artaud pretende destruir en su raíz, aquello cuya derivación, si no imposibilidad, denuncia incansablemente, aquello sobre lo que sus gritos no han dejado de abatirse rabiosamente. Pues lo que nos prometen sus aullidos, articulándose bajo los nombres de existencia, de carne, de vida, de teatro, de crueldad, es, antes de la locura y la obra, el sentido de un arte que no da lugar a obras, la existencia de un artista que no es ya la vía o la experiencia que dan acceso a otra cosa que ellas mismas, la existencia de una palabra que es cuerpo, de un cuerpo que es un teatro, de un teatro que es un texto puesto que no está ya al servicio de una escritura más antigua que él, a algún archi-texto o archi-palabra. (La escritura 240)

Esto porque Artaud, en palabras de Derrida, "nos enseña esa unidad anterior a la disociación" (240) que es la dimensión sensible que se detiene en las cualidades que emergen desde cuerpo humano o animal como forma de conocimiento y en donde lo que se dice y hace adquiere un plus desde el cómo se llevan a cabo junto a la fuerza corporal que materializa la voz, sus sonidos y la escucha atenta que desplegamos en la experiencia común.

Por su parte, Hans-Thies Lehmann nos propone en su Teatro Posdramático las posibles transformaciones de la voz en estas nuevas formas de teatro. La materialidad performativa de la voz es destacada por Lehmann como una de las 
experimentaciones que proponen las nuevas formas teatrales. Así a los esfuerzos, jadeos, al ritmo, el sonido y grito, así como a los quiebres y alargamientos de la voz en escena, lo define Hans-Thies Lehmann como la "physis de la voz" (268) en la medida que:

la realidad corporal crea un déficit de sentido: lo que quiera que aparezca en la escena en términos de significado es siempre llevado a cabo un paso más allá de su consistencia a través de la sensorialidad del cuerpo". Y continúa la cita enfatizando que "el sentido es desgajado del torbellino preconceptual de la certeza sensorial que, a partir de cada posicionamiento estable (tesis) de un texto, destaca su lado performativo, su carácter despreocupado de toda verdad, su profunda inconsistencia. (267)

Aquel déficit de sentido que abre la sensorialidad del cuerpo en escena, deja emerger para nuestro análisis, lo que denominamos al interior de la teatrología, la dimensión performativa de la performance, potenciando, en el caso de Zona de dolor 1, la unión de la "physis de la voz" de Eltit a través del recurso auditivo mediado por el video que hemos estado utilizando. Teniendo presentes estos aspectos, quisiera plantear mis reflexiones en torno a Zona de dolor 1 a partir de la inconsistencia performativa que plantea Lehmann, poniendo de relieve para el análisis el arranco y la vibración de la voz, así como su diseminación a propósito de su sonorización mediada. Complementando lo anterior, Erika Fischer-Lichte, en sintonía con las ideas de Artaud revisadas antes, argumenta que "la voz suena al arrancársele al cuerpo y vibra en el espacio" manifestándose "al gritar, suspirar, gemir, sollozar o reír. Todas esas actividades se producen en procesos que, innegablemente, afectan a todo el cuerpo, que se dobla, se contorsiona o se tensa al máximo. Asimismo, estas expresiones de la voz exentas de palabras pueden conmover corporalmente hasta lo más profundo a quien las oye" (255).

Planteamos con estas perspectivas teóricas que las intensidades de los usos de la voz, los sonidos que emergen del performar, por parte de Diamela Eltit, viene 
cargada de su sentido propio, casi como una vivencia paralela al texto, la historia o situación que narrada el texto leído, pues se auto-sustenta en su materialidad-cuerpo y se expande por el espacio llegando en forma de vibración a los cuerpos de cada uno de los "espectadores-oyentes" como algo anterior a "lo que se dice". De este modo, se desplaza, a momentos, la importancia del contenido del texto (la narración de las situaciones que remarca la lectura del extracto de Lumpérica que, no cabe duda, contiene una enorme dosis de la vivencia del corte en la carne materializado por Eltit en su Zonas de dolor 1), por el canal material de la voz o por su pura sonoridad. Por lo anterior se genera en el receptor, así nuestra hipótesis, un déficit de "sentido" en el que la importancia ya no está concentrada únicamente en lo que la historia necesita contarnos acerca de los hechos que estructuran el relato escrito de Lumpérica, sino que en la forma en que esta información sonora logra, de un modo complementario, inundar por completo el espacio de la experiencia, como si fuera otro cuerpo/actor más.

De este modo, la "pérdida de sentido" se manifiesta casi como una dinámica que envuelve de modo oscilante la performance, conduciendo su movilidad y ritmo. Pero: ¿de qué forma lo hace? Esta operación no es lineal sino rítmica, es decir, la pérdida de la lógica que debiera seguir tradicionalmente una performance como Zona de dolor 1 no nos conduce a entender cada vez menos, o a una incapacidad total de poder hilar los hechos de forma tradicional, es decir, lineal y creciente, sino que evoluciona "rítmicamente" con la construcción de la lectura que hace Eltit, dando la posibilidad de nunca caer en el mero entendimiento lógico de los hechos, para así tener acceso a otra dimensión alejada del contenido del texto. Una dimensión de voces y envoltura sonora total que se perfila o deja entender como una narración paralela que nos entrega otro tipo de "informaciones" en torno a lo que dice el texto leído, primordialmente sensoriales (performativas).

Esta dimensión performativa y material del sonido que envuelve el espacio, o esta vibración de la voz en el espacio cobra gran relevancia en nuestra aproximación al video Zonas de dolor 1, dado que es la matriz que guía el trabajo, tanto de desde lo que más arriba denominé la "physis de la voz" como su 
“diseminación” a propósito de la recepción que hago en el visionado del video que potencia, aún más, la sonoridad vocal, generando vínculos físicos, efectos en el espectador. La intensidad de los usos de la voz con la que se presenta Diamela Eltit, deja emerger un registro agudo en una repetición que constituye un ritmo ondulante. Las vocales son alargadas en ciertos momentos mientras que otras sílabas se dicen estrepitosamente, con prisa, sin mayor énfasis en la duración, ni menos del entendimiento en los términos lexicables tradicionales. La agudeza del registro vocal, sobre todo en la pronunciación de algunas vocales, produce un quiebre vocal casi imperceptible. Inicialmente se distinguen la mayoría de las palabras, luego estas son disueltas en la velocidad de su enunciación, apareciendo de vez en cuando algunas "uñas de los pies”. O cuando la voz de Eltit dice: “...por eso sus uñas más pequeñas comparecen...", mientras lee un párrafo más de sus borradores de Lumpérica. La voz de Diamela Eltit, configurada por la velocidad, la altura y la cadencia o el espectro de notas que transita, se mantiene en un espacio delimitado, es un molde formal que permite la irrupción de diversos fonemas y palabras que aparecen y desaparecen en esta estructura. Hay palabras que sucumben a la velocidad mientras que otras son explotadas en consonantes y vocales por estas características.

Algunas de las palabras utilizadas aparecen con mayor énfasis producto de la repetición; "uñas de los pies" "dedos de los pies". Otras que aparecen debido a la explosión (de volumen, de acentuación) son: "las leyes" "espanto" "formación ósea" "pervertir" "los pobres" "voluntariamente" y "los colores". Parece que, enfatizando las cualidades de la voz, Eltit quisiera remarcar tanto la necesidad de presentar su cuerpo como el espanto por que transitaba la clase obrera, los desplazados y el pueblo chileno en tiempo de dictadura. Como sonidos del dolor y la rabia compartida se hacen presente fonemas como "jueces" y "asambleístas" que sucumben en la velocidad del habla y que pude identificar en segundas y terceras audiciones, mientras que el grueso de los elementos "sucumbidos" son inidentificables y desaparecen. Desaparecen como la verdad y la justicia que no logran encontrar, hasta hoy, los familiares de detenidos desaparecidos por la 
violencia dictatorial y por la violencia que el estado ejerce, hoy, contra el pueblo Mapuche.

A lo largo de este ensayo he optado por expandir las lecturas del arte acción chileno intentando abordar la performance Zona de dolor 1 o "Maipú" de Diamela Eltit. El rescate historiográfico de las filiaciones nos llevó a concentrar en análisis en la intensificación de la voz de Eltit, situando el interés en el esfuerzo, los jadeos, el ritmo, el sonido y el grito con el que trabaja Diamela Eltit durante gran parte de la performance. Desde este prisma es ella quien insistente y calculadamente enfatiza juegos con las entonaciones de su voz, agudizándola, acelerándola, manteniendo un alto grado de tensión y atención por parte de los receptores. A través de estas estrategias de intensificación de la voz y el sonido, Eltit pone énfasis es la materialidad de la voz. Con Artaud, Diamela Eltit dispone, ante quienes la escuchamos y vemos en el video, de las sutilezas en el pronunciamiento de la voz como fenómenos acústico y eminentemente performativo.

\section{Bibliografía}

Artaud, Antonin. El teatro y su doble. Barcelona: Edhasa Editores, 2011. Impreso . El arte y la muerte /Otros escritos. Buenos Aires: Caja Negra Editores, 2005. Impreso.

Bachmann-Medick, Doris. Cultural Turns: Neuorientierungen in den Kulturwissenschaften. Hamburg: Rowohlt Verlag, 2014. Impreso

Barrientos, Mónica. "La construcción estética de la imagen en la performance Zonas de dolor de Diamela Eltit", en revista Aisthesis 61, Santiago, jul. 2017. Web. 25 de abril, 2019. 
CATEDRAL TOMADA: Revista de crítica literaria latinoamericana / Journal of Latin American Literary Criticism Gritos en la piel, sonidos del dolor. A propósito de Zona de Dolor 1 de Diamela Eltit

. (Ed.) No hay armazón que la sostenga. Entrevistas a Diamela Eltit.

Talca: Editorial Universidad de Talca, 2017. Impreso

Barthes. Roland. Lo obvio y lo obtuso. Barcelona: Editorial Paidos, 2009.

Impreso.

Berghaus, Günter. New approaches to theatre studies and performance analysis. Tübingen: Max Niemeyer Verlag, 2001. Impreso.

Derrida. Jacques. La escritura y la diferencia. Barcelona: Editorial Anthropos, 1989. Impreso.

Eltit, Damiela. Lumpérica. Santiago de Chile: Editorial Planeta, 2008. Impreso.

Fischer-Lichte, Erika. Estética de lo performativo. Madrid: Abada Editores, 2011. Impreso.

Galende. Federico. Filtraciones I. Conversaciones sobre arte en Chile (de los 60 's a los 80's). Santiago de Chile: Editorial Arcis / Editorial Cuarto Propio, 2007. Impreso.

Gonzalez, Francisco, López, Leonora, Smith, Brian. Performance Art en Chile. Santiago de Chile: Ediciones Metales Pesados, 2016. Impreso.

Grumann, Andrés. "Performance: ¿disciplina o concepto umbral?”. Apuntes de Teatro 130, (2008): 126-138.

Kolesch, Doris. "Listen to the radio. Artaud's Radio-Stimmen(n)". Forum Modernes Theater 14 (1999): 115-143.

Lehmann, Hans-Thies. Teatro posdramático. Murcia: Ediciones Cendeac, 2013. Impreso.

Martin, Jacqueline and Sauter, Willmar. Understanding theatre: performance analysis in theory and practice. Stockholm. Theatre Studies , No 3, 1995. Impreso.

Neustadt, Robert. CADA DÍA: la creación de un arte social. Santiago de Chile: Editorial Cuarto Propio, 2001. Impreso.

Peters, Tomás. "Cartografía de una puesta en escena. De la enunciación de un concepto a su inscripción en los relatos: sobre cómo el concepto de Escena de Avanzada se describe/inscribe en la historia del arte chileno". 
Tesis grado de Magíster en Teoría e Historio de la Artes, Universidad de Chile, 2011. Electrónico.

Piña, Juan Andrés. "Escrito sobre un cuerpo". Ed. Mónica Barrientos. No hay armazón que la sostenga. Entrevistas a Diamela Eltit. Talca: Editorial Universidad de Talca, 2017. 207-235. Impreso

Richard, Nelly. Márgenes e Instituciones. Arte en Chile desde 1973. Santiago de Chile: Ediciones Metales Pesados, 2007. Impreso.

. "Lo político en el arte. Arte, política e instituciones", en recurso electrónico: Hemispheric Institute. E-misférica 6.2. Web. 23 de abril, 2019.

Schrödl, Jenny. Vokale Intensitäten. Zur Ästhetik der Stimme im postdramatischen Theater. Bielefeld: Transcript Verlag, 2012. Impreso.

Weiss, Allen S. Phantasmic Radio. Durhman \& London: Duke University Press, 2005. Impreso.

Vega, Francisco, "Despojos de psique. Trauma, inscripción y archivo en Tentativa Artaud de Ronald Kay". Aisthesis 64 (2018), 299-319. Impreso.

Zamorano, César. "Revista de Crítica Cultural: pensando (en) la transición", Universuty of Pittsburgh, 2014. Electrónico. 